\title{
Student-Led Initiative Promoting K-5 Hands-on Engineering Education
}

\section{Ms. Shreya Gupta, Bit Project, College of Engineering, UC Davis}

Shreya Gupta is the co-founder and Director of Primary Education at Bit Project. She directly oversees an interdisciplinary group of 25 undergraduate students to write and implement STEM activities in schools across California. Within the span of four months, she has successfully integrated custom-built STEM education hardware and software at a public elementary school. In addition, she has held professional development workshops, organized over 35 volunteering events, and spearheaded K-5 collaborations with Microsoft and Keysight Technologies.

\section{Mr. Dong Gyun Kim, Bit Project, College of Engineering, UC Davis}

Daniel Kim is the co-founder and president of Bit Project, a student initiative that has reached over 1800 K-12 students since its founding in Spring 2019. He has led educational technology collaborations with community nonprofits and industry leaders o make technology more accessible in K-12 Classrooms.

\section{Ms. Victoria Kang Li Xu, Bit Project, College of Engineering, UC Davis}

Victoria $\mathrm{Xu}$ is an undergraduate English and Psychology student who serves as the lead technical writer and editor for Bit Project. She works directly with various Bit Project teams to proofread for grammatical and organizational issues in technical, formal, and casual writing. She has primarily written and edited lesson plans for K-12 STEM education, proposals to university departments for educational collaboration, and instructional guides on using industry-standard programs. 


\title{
Implementing Student-Led Outreach Programs for K-5 Engineering Education
}

\begin{abstract}
In contrast to existing university outreach programs, Bit Project's undergraduate curriculum developers produce student and teacher manuals for use in class. Manuals encourage exploration processes for data collection and presentation, promote teacher involvement in classroom events, and provide teachers training for successful curriculum implementation. Activities in the curriculum are tailored for various levels of learning, allowing accessibility to all students regardless of their educational background. Each activity is designed to foster open-ended problem solving, creativity, teamwork, and intellectual discussion. A four-week pilot program initiated in June 2019 integrated robotics activities into existing mathematics curriculum for second and third grade classes. This experience provided valuable insight on how STEM lessons help create a more balanced curriculum. Additionally, a yearlong pilot program for K-5 implemented in October 2019 was updated weekly based on feedback to concurrently improve and expand upon it.
\end{abstract}

\section{Introduction}

There currently exist multiple student-organized initiatives that implement K-12 outreach programs including Society of Women Engineers, Black Engineers Association, and Chicano and Latino Engineers and Scientists Society. However, from interviews with student leaders, we found that a lot of resources and time were spent on logistical details instead of valuable instruction and mentorship. Organizations established annual outreach events for limited numbers of students as they struggled to obtain the financial or human resources needed to bring hands-on education programs to classes.

Addressing these problems, Bit Project is a student organization at UC Davis that was created to provide students the resources needed to bring hands-on activities to the classroom. For undergraduate engineering students, working with and mentoring younger students is a way to develop strong interpersonal, communication, and leadership skills. Bit Project consolidates logistics for outreach into one organization and gives students a chance to apply undergraduate engineering education into real-life scenarios. The various outreach events create a platform for students who want to take time to connect with their communities. Promoting undergraduate students' involvement in primary education encourages students to pursue professional education degrees and provides prospective educators with classroom experience.

Due to the rise of technical careers and increasing demand for job applicants with strong STEM backgrounds, integrating hands-on STEM into early education is especially demanding for teachers with non-STEM backgrounds [1]. The current lack of STEM-centric education increases restrictions on teachers to integrate project-based learning into the classroom, as well as the pressure to build an inclusive education system for all. According to research conducted to determine the effectiveness of teacher preparation for STEM subjects, students consistently achieved higher academic results learning under teachers who already had higher education certification in an academic field, STEM or otherwise [2]. Additionally, elementary school educators rate their confidence in teaching math and literature at approximately $80 \%$, while they 
feel significantly less prepared to teach areas of science with an average rating of $40 \%$ [2]. The retention rate of teachers in primary education is also highest for teachers who are not certified in STEM fields [2]. Community involvement in education has demonstrated, for the children involved, higher engagement and interest in challenging curricula, higher academic achievements, and positive changes in behaviors [8]. Based on this data, it is evident that there is a critical need to help teachers from non-STEM backgrounds integrate STEM subjects into their classrooms.

A team of interdisciplinary undergraduate student developers at UC Davis have organized a program that involves the student community in supporting teachers and sharing resources to increase project-based STEM education. Within Bit Project, undergraduate students work together to develop comprehensive solutions for STEM education to transform the learning experience for young students, including classroom events, after-school programs, and summer camps.

\section{Project Design and Execution}

\section{Pilot Program}

In June 2019, university students implemented a four-week pilot program in second and third grade classes to integrate robotics into existing math lessons and add interactive elements for students while learning various topics. The program involved undergraduate volunteers assisting teachers in the classroom with the hands-on lesson.

During the first week, students were required to design the longest track possible to get a robot from one point to another on a restricted plot of land. The activity encouraged students to create multiple shorter tracks and piece them together. During the second week, they used robot tracks to calculate multiplication tables. Figure 1 shows students dividing tracks and calculating fractions with the robots in week 3. By the fourth week, students could utilize the skills acquired from prior weeks to create unique structures for the robots and determine the area and perimeter of their designs. The volunteers provided students with individual attention to help them succeed in these challenging hands-on math activities.

Teachers reported that students had higher engagement in activities and higher information retention rates in the robotics-based math lessons relative to classes without any interactive features. We realized that the program was, however, limited in its scope to math-based education and could have been more effective by including a range of other hands-on science and engineering lessons. 


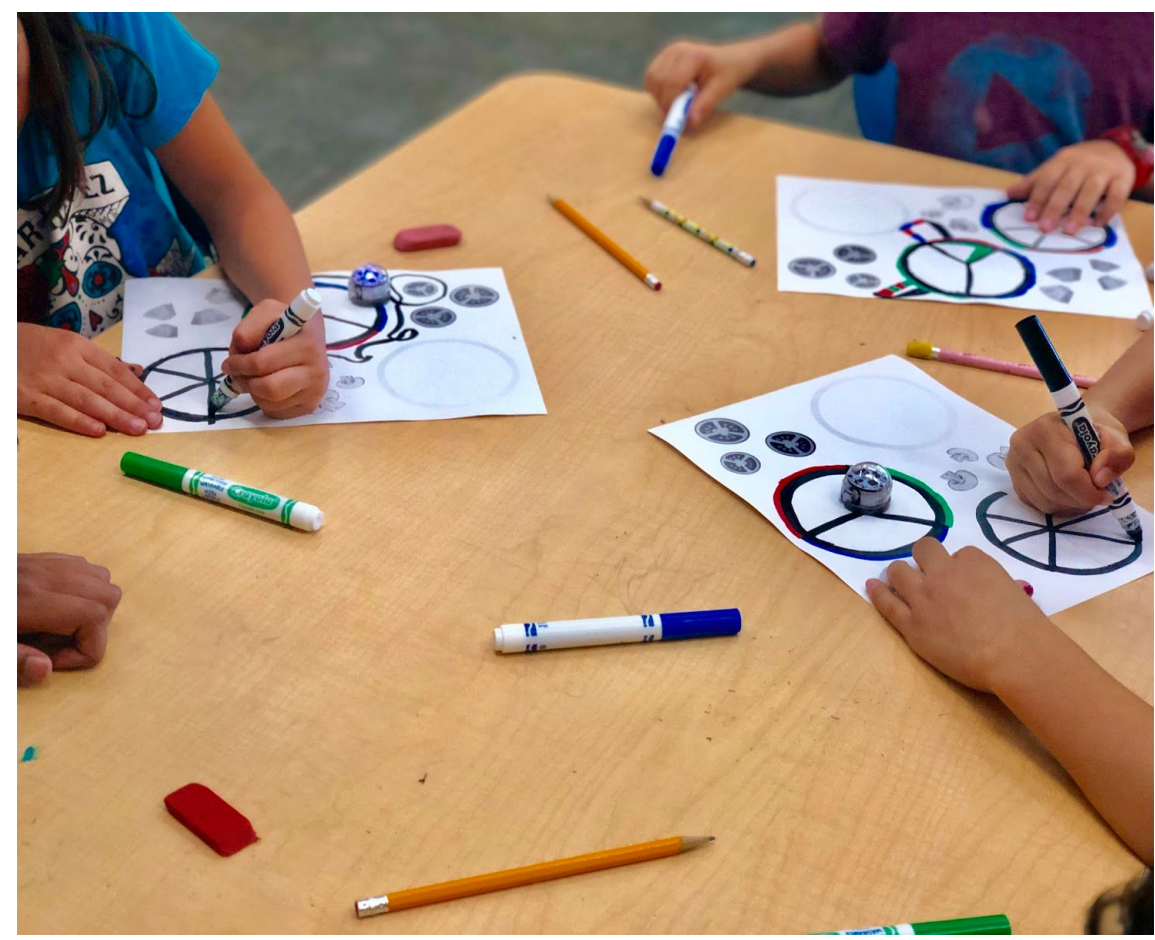

Figure 1: Students Learning About Division Using Robotics-Based Lessons

\section{Outreach Program}

Based on the response from the pilot program, Bit Project organizers have implemented an outreach program at Korematsu Elementary School designed to help educators integrate project-based learning into the classroom.

The structure of the organization involves curriculum developers, outreach coordinators, volunteer leads, and volunteers. Curriculum developers research, design, and develop hands-on activities; outreach coordinators are responsible for organizing lessons with elementary school classes and managing volunteers; volunteer leads direct groups of volunteers in events and facilitate communication between teachers and volunteers; and volunteers are trained in teaching activities and help conduct lessons.

The outreach program is supported by UC Davis's College of Engineering and is partnered with the Parent Teacher Organization (PTO) at Korematsu Elementary School, which manages the volunteer approval process, acquiring parent permission for activities, and signing of consent forms and waivers. This program is a three-part solution to increase hands-on education in elementary schools. This includes lesson plans for hands-on STEM activities, a Volunteer Organization System to implement lessons and events, and Online Training Modules to prepare teachers and volunteers for teaching and assisting the lesson respectively.

The program provides a framework to facilitate getting involved in primary education for students interested in volunteering. We build the organization system through which teachers can set-up volunteering-based events and have knowledgeable volunteers help introduce innovative lessons relevant to current curriculum. 


\section{Interdisciplinary Curriculum Development}

\section{Creation of Lesson Plans}

The lesson plans at Korematsu Elementary School's outreach events were implemented through interdisciplinary curriculum development, testing, and an extensive formalized improvement pipeline. Undergraduate students from the College of Engineering and Letters and Sciences are leading the efforts to design and execute hands-on STEM lessons for K-5th grade classes.

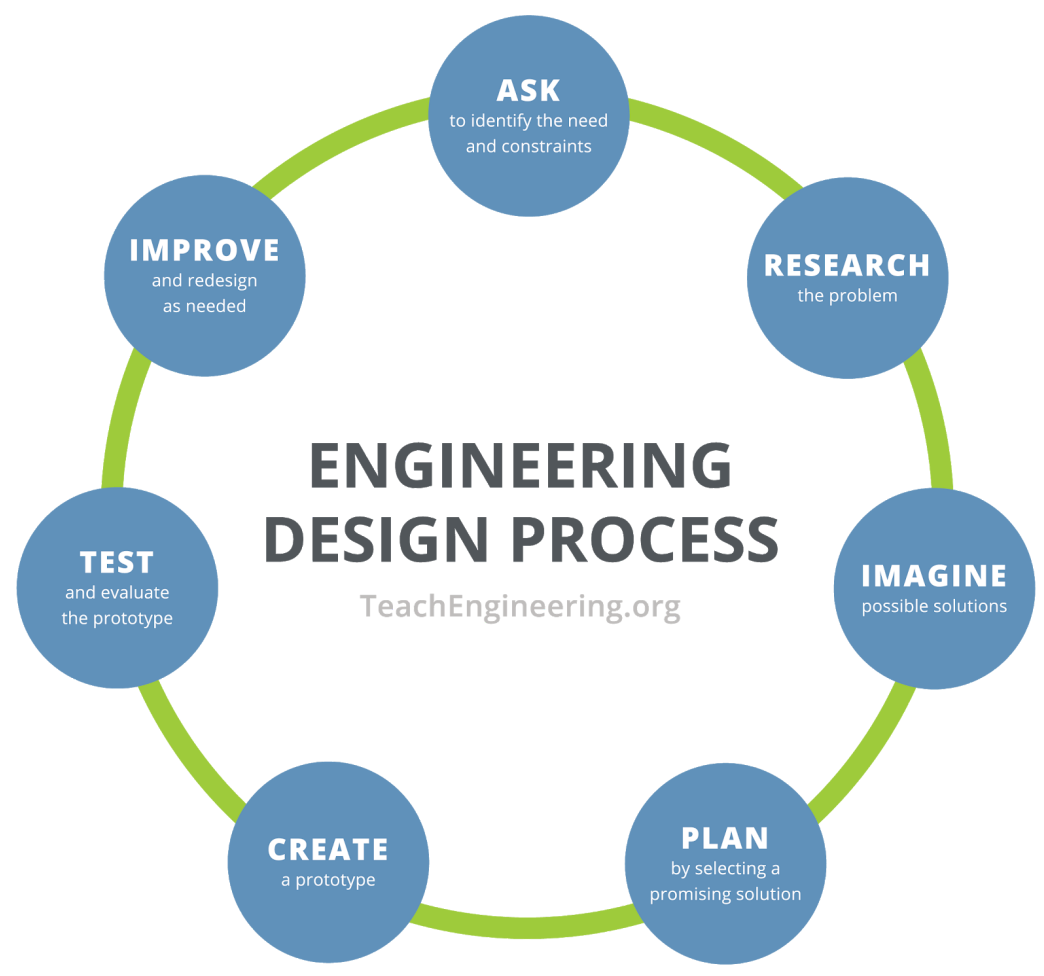

Figure 2: Engineering Design Process by TeachEngineering [9]

Our developers design lessons following the development flow from TeachEngineering in Figure 2. Choosing activities to convert into lesson plans begins with researching academic standards such as the Next Generation Science Standards (NGSS) and Common Core Standards (CCS). Due to the growing number of careers that require a strong foundation in science and mathematics, the cross-disciplinary NGSS assure quality education in "content and practice" and prepare students for success in higher education and the pursuit of advanced careers [4]. Curriculum developers create hands-on engineering activities around the performance expectations of NGSS, including Science and Engineering Practices, Disciplinary Core Ideas, Crosscutting Concepts, and Common Core State Standard Connections. Hands-on engineering design projects are developed into lesson plans that require students to think outside the box.

When designing the procedures, developers focus on implementing overarching concepts that students need to design and execute solutions to problems. Students are expected to use their 
findings to create and test hypotheses to determine the next step instead of referring to a pre-written procedure. Discussion questions support group collaboration and encourage critical thinking to guide students through the lesson.
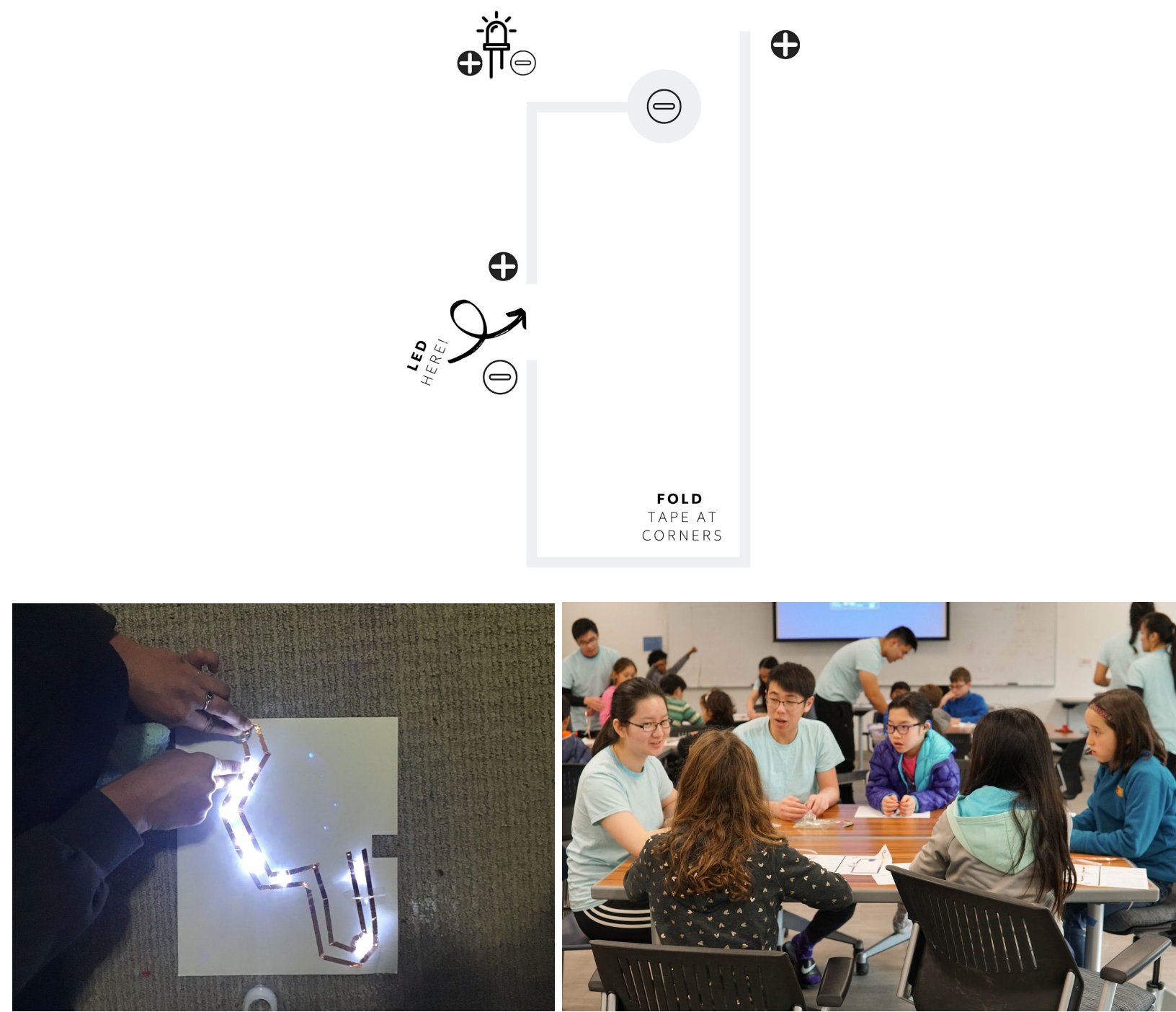

Figure 3: Paper Circuits Lesson (Series Circuit Diagram (top), Parallel Circuit Student Project (bottom left), Students working with Undergraduate Volunteers (bottom right))

Figure 3 shows the Paper Circuits lesson developed for the outreach program, in which students study properties of electricity by building various series and parallel circuits with copper tape, LEDs, and a battery. The activity follows the 4-PS3-2 NGSS standard to practice using observations to build evidence for energy transfer [5]. Building multiple permutations of series and parallel circuits helps students analyze how electricity flows to make LEDs light up.

\section{Testing}

Each lesson plan and associated project is tested out by undergraduate developers before being released to the public. Developers conduct run-throughs of lesson plans with undergraduate 
volunteers to fix bugs in the design and implementation and find affordable, appropriate materials to maintain the lesson's feasibility in the classroom. The diction used in the lessons is reviewed to guarantee that it is suitable for its target grade level. Such testing includes revising concept definitions, procedures, and discussion questions to convey understandable information.

\section{$\underline{\text { Formalized Pipeline }}$}

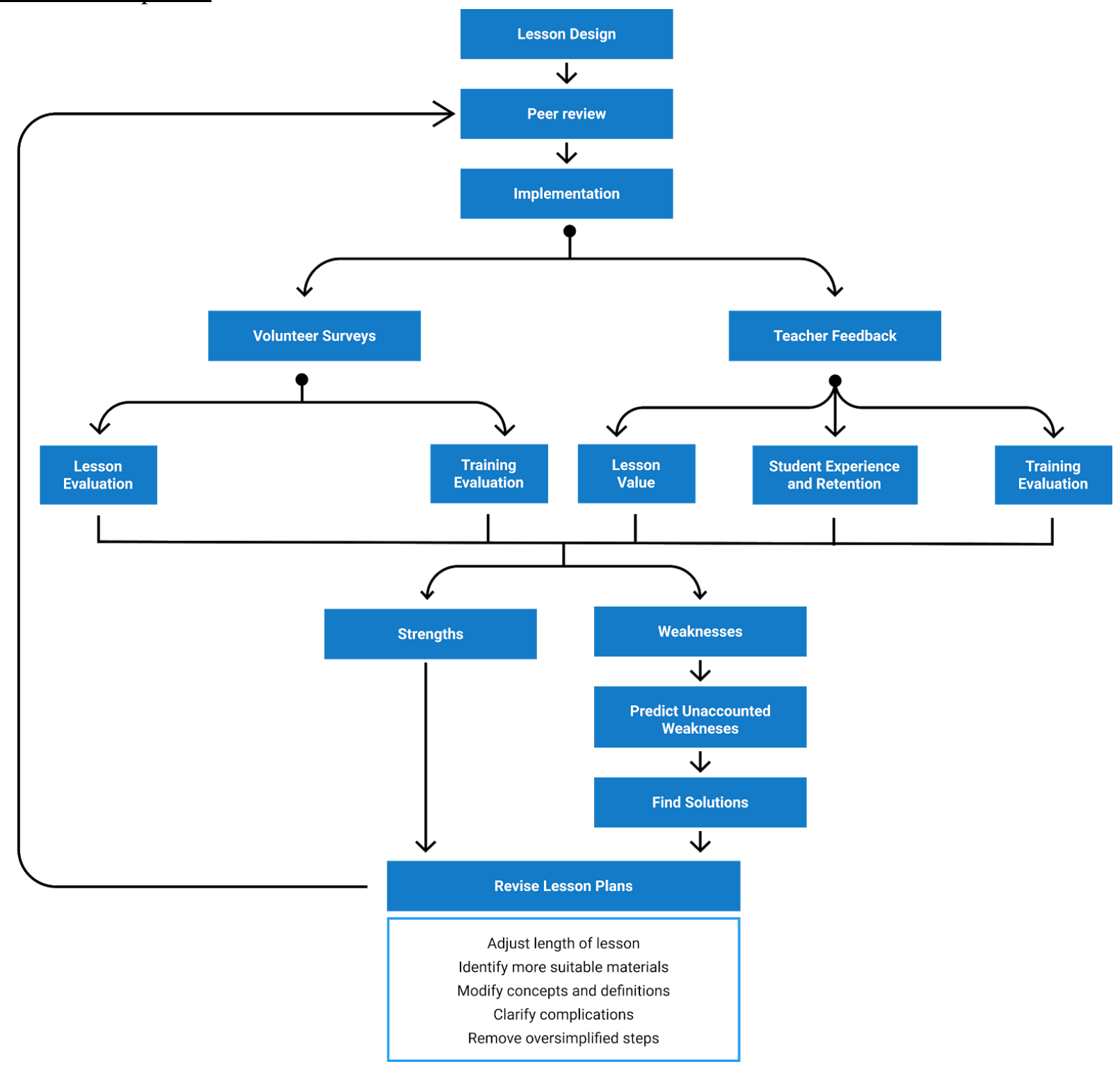

Figure 4: Formalized Pipeline of Work

A formalized pipeline of reviewing and editing classroom activities, as presented in Figure 4, plays a major role in the long-term success of this program. Through this reviewing process, teachers and volunteers are able to provide feedback through forms and surveys, describe their experience, and improve the lesson plans for future users. 
Teacher feedback is provided through an online response form that inquires about their experience with the lesson plan and volunteers. Teachers rate the activity in terms of their overall experience, students' reception to the activity, their experience with the volunteers, their involvement in the lesson, how likely they would be to integrate the lesson into their current curriculum, and how comfortable they would be leading a similar activity in the future. These ratings allow developers to determine strengths and weaknesses of the lesson plans and volunteer experiences, and create a plan of action to improve other activities.

Volunteers are surveyed by organizers after each event to determine areas that need improvement in the lesson plan from a different perspective. Feedback is given based on how comfortable volunteers felt working with the students, how prepared they felt in following the lesson plan, students' understanding of the lesson, and their experience working with the teacher.

Curriculum developers analyze the feedback from teachers and volunteers to revise the lessons. Sometimes, lessons do not initially match the one-hour limit, so developers alter activity lengths to comply with the given class time and allow students to cover all of the content. Problems with specific materials are fixed by finding replacements, and difficult concepts are expanded upon to help students learn more easily. Complicated procedures are simplified to help students follow lessons, while oversimplified steps are removed to encourage critical thinking to solve problems.

\section{Volunteer Organization System}

Outreach coordinators reach out to all colleges, majors, and various student organizations to get more diverse students involved in the events; to date, coordinators have collected a pool of over 175 students. Various engineering, diversity, and community service student organizations as well as members of the UC Davis faculty are part of the volunteer pool and help expand community involvement.

Volunteers sign up for individual events through an online calendar, which is regularly updated with upcoming outreach events. A group of five to seven student volunteers join each event. These students are responsible for arranging materials, setting up the lesson, and helping create the most adequate learning environment for the students. Each group is escorted by a designated volunteer lead, who acts as the liaison between the teacher and volunteers, controls emergency situations, and manages student-volunteer behavior as needed.

\section{Online Training Modules}

Volunteers are trained through the Online Training Modules in classroom etiquette, event rules and organization, and activity implementation to efficiently support teachers in conducting the activities. The Modules teach undergraduate students to efficiently communicate with younger students, create a comfortable learning environment, and practice discipline and safety in the classroom. 

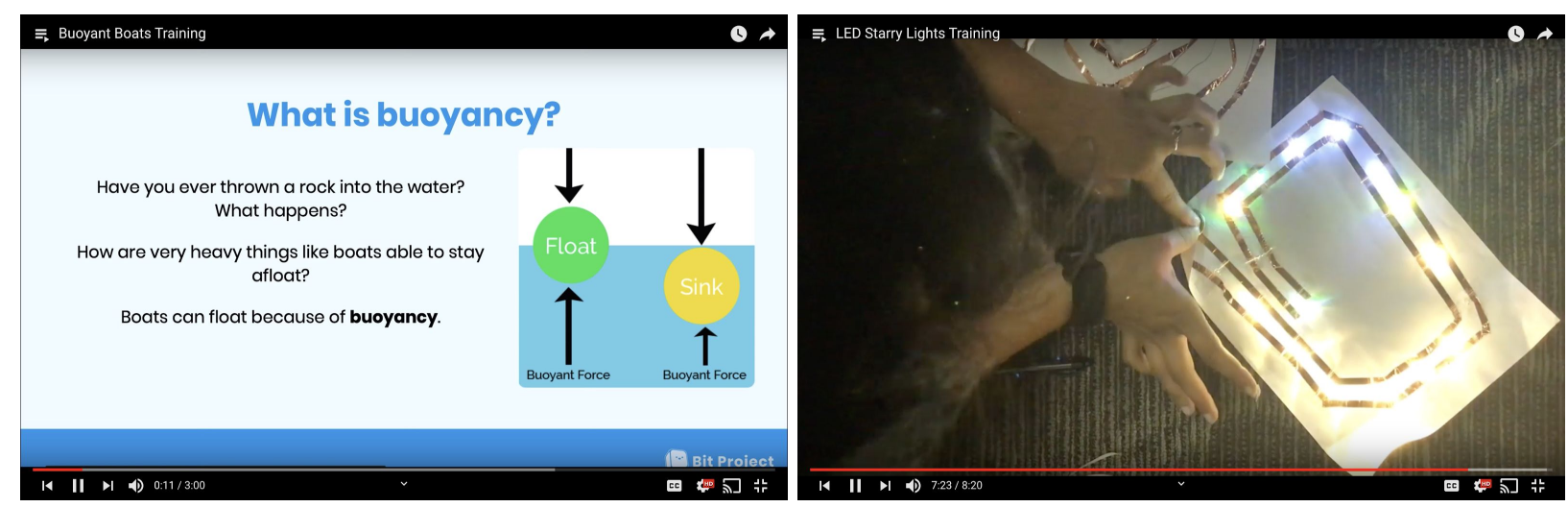

Figure 5: Training Videos [6][7]

As shown in Figure 5, developers create video guides to walk teachers and volunteers through required materials for the activity, how to create the project with instructions for guiding the students, and how to promote creativity so that students can expand upon their projects. Videos explain the overarching goals of the lessons, define major concepts that students need to build the projects, and cover discussion questions that have multi-layered answers. During the actual lessons, volunteers first lead students through a code of conduct. Then, they go over the lesson plan [6] and guide them through the project online [7].

\section{Data Collection \& Evaluation}

Feedback Collection Process

Conversational interviews with volunteers following events are held by outreach coordinators. These interviews include questions that evaluate the lesson's value for the students participating, the teacher leading the lesson, and for the volunteers themselves. In addition to interviews and surveys, we use numerical ratings to help us measure the value of the program's different aspects and recognize particularly strong or weak spots. Any aspects of the program such as the training or actual teaching were rated on a scale of 1-10, 1 being the lowest value and 10 being the highest. The numerical scales allow developers to determine areas of feedback that may need immediate attention.

The feedback collection processes follow three main criteria: quality of preparation, execution of the lesson, and suggestions for future implementations. These areas of focus help identify strengths and weaknesses in the program's execution and determine improvements to make for future lessons. Provisionally, we are evaluating student progress through the volunteer and teacher feedback.

\section{Volunteer Data Collection}

Once the lesson plan is brought into classrooms, volunteers conduct analyses of the activities to determine any flaws, concerns, or areas for improvement.

Questions asked in the volunteer feedback form include:

- How helpful was the volunteer training?

- What more can we do to prepare volunteers? 
- What are some areas in which you felt unprepared as a volunteer?

- What are some aspects of training that made a positive impact on your experience?

- Were there any problems you or others had during the event?

Anonymous volunteer responses include:

- The materials should be prepared and organized better before the event starts; however, we were prepared with the background of the activity and the children enjoyed the activity and heavily participated.

- It was an interactive way to learn and the students had fun with the hands-on activity since [the lesson] was challenging and engaging.

The lowest rating was received by the training process for volunteers at an average of 5.7/10. Prior to the current training modules system, training had been conducted over group video calls and focused heavily on behavioral training. We found that the previous training system did not adequately prepare volunteers for the project building aspect of the lesson. Based on interviews with 88 volunteers over the first three months of the program, the majority proposed building a more extensive training system. We responded by implementing new video-based modules described in the Online Training Modules section above. Volunteers reacted positively, saying that they understood lessons well and felt comfortable mentoring students in new projects. We will be collecting more feedback for the new system in the coming months.

\section{Teacher Data Collection}

Teacher feedback is crucial for maintaining high-quality lessons and ensuring student engagement. Anonymous online forms allow teachers to express their honest opinions about the events and detail constructive advice on how to improve lessons for future events.

Questions asked in the teacher feedback form include:

- What did you like about this activity?

- What did you NOT like about this activity?

- How receptive were students to the activity?

- Do you have any advice for volunteers to help improve future events?

- How involved did you feel in the activity?

- How well would you say the event complemented your class and current lesson plan?

The program received a rating of 7.2/10, indicating that volunteer training was lacking in some areas, but that volunteers were still valuable assets to the lesson. The likelihood of teachers to integrate the lessons into their regular curriculum was rated at 7.8/10, indicating that the program was well-received by the teachers but could still benefit from some modifications. Overall, the teachers rated student reception the highest out of all of the categories at 9.5/10, guaranteeing that the students were engaged in this new learning environment.

Anonymous teacher responses include:

- "Each group exercised critical thinking and communicating with other students and us volunteers to solve problems and improve their bridges. The enthusiasm of the 
second-graders at Korematsu Elementary to participate in and learn about Paper Bridge warmed my heart."

- "Working with students at Korematsu Elementary School over the past three months made me realize how important it is to introduce students to science at an early age and help them analyze their surroundings. With proper guidance and a strong, innovative STEM curriculum, students will develop a more balanced academic skill set that will last a lifetime."

- "I suggest having visuals like a big chart with pictures and a few words for all kids to see and [university] students be more dynamic in their presenting, but I really appreciate the willingness of the [university] students to come out and try something new like this."

This feedback allowed curriculum developers to evaluate the program and make the modifications described above.

\section{Commitment to Diversity}

According to the Assessment of Diversity in America's Teaching Force, academic performance increases when students are taught by "ethnically diverse and culturally competent teachers" [3]. When young minority students are mentored by a diverse group of experts, they feel empowered to achieve higher levels of success and become the next generation of leaders. Since diversity cultivates innovation in solving real-world problems, Bit Project's outreach program invites developers and volunteers from various socio-economic backgrounds to create STEM-based education practices in which students can celebrate their unique qualities and experiences.

Figure 6 provides statistics of the academic fields Bit Project members are currently pursuing. A large portion of our members study various subjects in science, technology, and engineering, and develop a range of lesson plans to build a comprehensive program. The range of ethnicities in Bit Project is presented in Figure 7, while the gender distribution is shown in Figure 8. Diversity amongst our program organizers and developers is crucial to ensure that the lessons built are suitable for all young students and teachers. Promoting diversity amongst all of our volunteers helps strengthen Bit Project's ability to identify and mitigate shortcomings in vastly different education systems. 
Developers and Volunteers by Majors

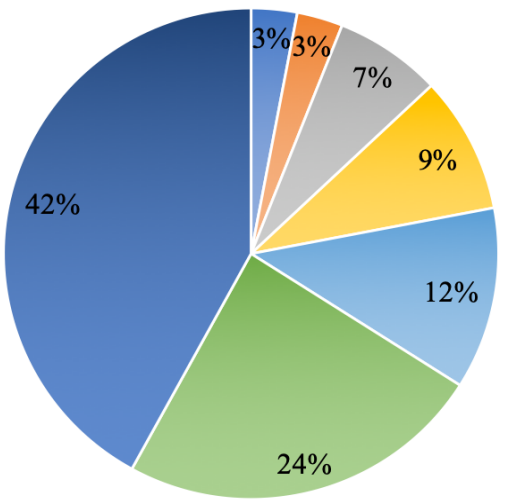

- Social Science

- Design

$\square$ Physical Science

math/Statistics

- Biological Sciences

- Computer/Electrical Engineering

- Computer Science/Cognitive Science

Figure 6: Developers and Volunteers by Major

Developers and Volunteers by Ethnicities

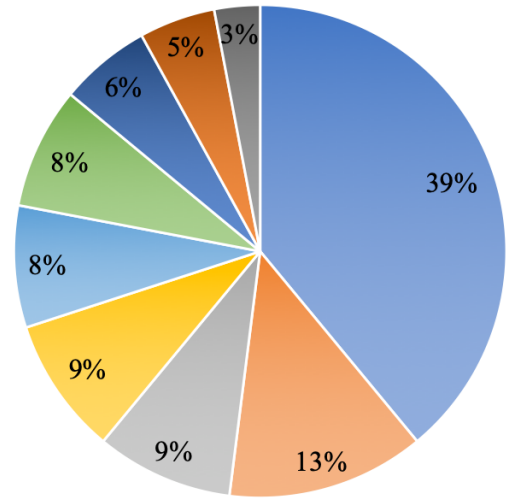

- Asian Americans

- South-East Asian

East Asian

- European

- South Asian

Multi-Ethnicity

- African-American

- Caucasian

- Hispanic

\section{Figure 7: Developers and Volunteers by Ethnicities}

\section{Developers and Volunteers Gender Distribution}

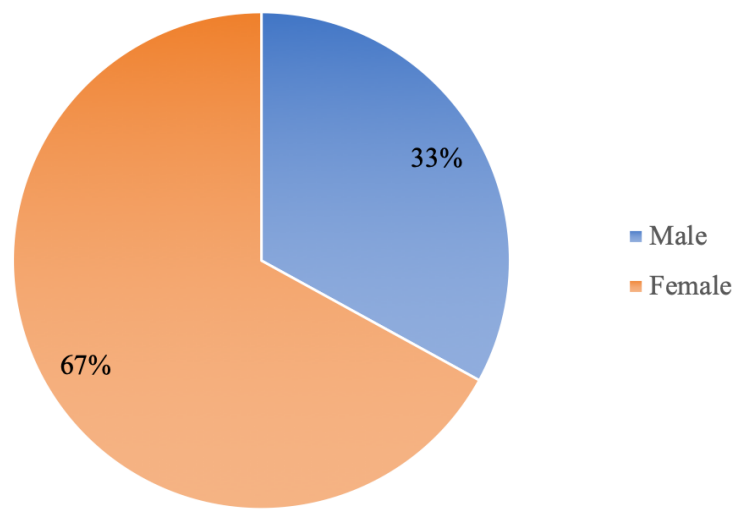

Figure 8: Developers and Volunteers Gender Distribution

Our team aims to diversify the volunteer pool by collaborating with more student organizations on campus and integrating the program at other universities. 


\section{Sustainability \& Future Plans}

As an outreach program focused on bringing communities together, it is important that we are able to provide resources to other university students developing similar programs. We offer training and organizational support to allow undergraduates to implement such outreach within their own communities. Organizers will be guided through the process of developing educational content, partnering with schools, and acquiring industry sponsorships to help sustain the program. Additionally, we will provide all paperwork, including waiver and consent form templates, required to start their program. We hope that, through our expansion, we can diversify our community of content developers and extend our resources to as many underprivileged schools as possible. The expansion of our outreach program guarantees a unique learning experience that will strengthen students' foundations in core STEM subjects.

\section{Conclusion}

Organized by undergraduate students, the Bit Project outreach program grants teachers access to resources for easy integration of project-based learning into their classes. An analysis of the first implementation of the outreach program received positive feedback and promise for long-term continuation at the school. As a student-led effort, Bit Project recruits new curriculum developers and outreach coordinators every academic quarter, ensuring a continuous stream of lesson plans.

Feedback from volunteers and teachers on training methods and lessons allows the program to better serve users and encourages student developers and volunteers to continuously improve upon it. With administrative support from teachers and parents, financial support from corporations, and the voluntary efforts of university students and company employees, the program continues to empower student organizations to expand the outreach to more communities. 


\section{References:}

[1] Milner-Bolotin M (2018) "Evidence-Based Research in STEM Teacher Education: From Theory to Practice," Front. Educ. [Online]. Available:

https://www.frontiersin.org/articles/10.3389/feduc.2018.00092/full. [Accessed Jan. 25, 2020].

[2] "4 The K-12 Science Teaching Workforce," National Academies of Sciences, Engineering, and Medicine. 2015. Science Teachers' Learning: Enhancing Opportunities, Creating Supportive Contexts. Washington, DC: The National Academies Press. [Online]. Available:

https://www.nap.edu/read/21836/chapter/6\#72. [Accessed Jan. 27, 2020].

[3] “Assessment of Diversity in America's Teaching Force: A Call to Action," National Collaborative on Diversity in the Teaching Force, Washington, D.C., October 2004.

[4] NGSS Lead States "Next Generation Science Standards: For States, By States (insert specific section title(s) being used if not referring to the entirety of the NGSS)," Washington, DC: The National Academies Press. [Online]. Available:

https://www.nextgenscience.org/understanding-standards/understanding-standards. [Accessed Jan. 21, 2020].

[5] National Research Council. 2012. "A Framework for K-12 Science Education: Practices, Crosscutting Concepts, and Core Ideas," Washington, DC: The National Academies Press. [Online]. Available: https://www.nextgenscience.org/pe/4-ps3-2-energy. [Accessed Jan. 27, 2020].

[6] Bit Project, Buoyant Boats Training, 2020. Accessed on: Jan. 31, 2020. [Streaming Video]. Available: YouTube.com database

[7] Bit Project, LED Starry Lights Training, 2020. Accessed on: Jan. 31, 2020. [Streaming Video]. Available: YouTube.com database

[8] Dennis Van Roekel "Parent, Family, Community Involvement in Education," National Education Association. [Online]. Available:

http://www.nea.org/assets/docs/PB11_ParentInvolvement08.pdf.

[9] "Engineering Design Process," TeachEngineering. [Online]. Available:

https://www.teachengineering.org/k12engineering/designprocess 